\title{
Research Progress of VOCs Emission Accounting Method for Storage Tanks in Petrochemical Enterprises
}

\author{
WANG Lingzhi ${ }^{1,}$ a , GONG Huanzhang ${ }^{1, b}$, WU Peizhao ${ }^{1, c}$, LI Wei $^{1, \mathrm{~d}}$, WANG \\ Zhansheng ${ }^{2, e}$ \\ ${ }^{1}$ Key Laboratory of Regional Energy System Optimization, Ministry of Education, North China \\ Electric Power University, Beijing, 102206, China \\ ${ }^{2}$ CNPC Research Institute of Safety and Environmental Technique, Beijing, 102206, China \\ a849461352@qq.com, bgonghuanzhang54@gmail.com, c1669137798@qq.com, \\ d925657837@qq.com, ${ }^{e} 470391485 @ q q . c o m$
}

\section{Keywords: Petrochemical Enterprises; storage tanks; VOCs; calculation method}

Abstract. In consideration of Chinese policy on comprehensive regulation of volatile organic compounds(VOCs) and sewage charges, several methods for quantitative calculation of respiratory loss in crude oil tanks are analyzed and compared to evaluate the VOCs emission of petrochemical enterprises reasonably, including United States Environmental Protection Agency (EPA) recommended method, Petroleum depot energy saving design guidelines recommended method, emission coefficient method, Loss of liquid petroleum products in bulk estimation method and Technical guidelines for the preparation of emission inventories of atmospheric volatile organic compounds (Trial) recommended method. According to the production situation of petrochemical enterprises in China, selecting the appropriate calculation method, thus providing basis for VOCs source accounting, regional environmental planning and environmental monitoring for production and management departments.

\section{Introduction}

Petroleum plays an important role in the energy safety in China, oil production, storage and transportation industry is a pillar industry of the national economy. Limited by the existing technology, equipment conditions and other factors, part of the oil volatile into the atmosphere in the storage and transportation process, this phenomenon is called oil "breathing" loss [1]. According to the US survey report, the storage process accounted for the largest portion in the total emissions of oil, reaching 30\% [2]. Breathing loss will cause a huge loss of oil quantity, reduce the quality of oil, bring secondary effects; and volatile oil contains a large number of toxic and harmful gases [3], causing serious damage to the ecological environment, serious Endangering human health [4]; moreover, when the concentration of VOCs in the air reaches the explosion limit, the resulting explosion would leading significant loss of life and property [5]. Therefore, quantitative study of crude oil tank respiration loss has a positive and effective dual role in increasing the economic value of crude oil and control environmental pollution

\section{Recommended Method of EPA}

As early as 1962, the American Petroleum Institute (API) developed the first generation of fixed top tank emissions, and completed the revision in 1991. On the basis of this, the estimation procedure of the VOCs emission is given in Chapter 7 of the Pollutant Emission Factors (AP-42) published by the US Environmental Protection Agency (EPA) [6], a more detailed derivation process and formula were listed according to the tank type, loss type, type of breathing and type of oils . This method is applicable to calculate the emission of crude oil and petroleum products in petrochemical Enterprises.

Fixed Roof Tank Emissions. The following formula applies to vertical cylindrical tank with atmospheric pressure, but cannot be used to estimate the amount of petrochemical product loss for unstable or boiling stocks, mixed hydrocarbons and petrochemical with unknown vapor pressures. 


$$
L_{T}=365 \times W_{V} \times V_{V} \times K_{E} \times K_{S}+0.0010 \times M_{V} \times P_{V A} \times Q \times K_{N} \times K_{P}
$$

Where $L_{T}$ is the total loss, $\mathrm{lb} / \mathrm{yr} ; W_{V}$ is vapor density, $\mathrm{lb} / \mathrm{ft}^{3} ; V_{V}$ is storage space volume, $\mathrm{ft}^{3} ; K_{E}$ is vapor diffusion coefficient; $K_{S}$ is Steam saturation coefficient; $M_{V}$ is average molecular weight of volatile organic liquids in tanks, $\mathrm{lb} / \mathrm{lb}$-mole; $P_{V A}$ is Tank steam pressure at mean liquid temperature, psia; $Q$ is Annual turnover; $K_{N}$ is turnover coefficient; $K_{P}$ is material coefficient.

Floating Roof Tank Emissions. The following formula can only be used in the calculation of floating roof tank emissions, cannot be used to estimate the amount of petrochemical product loss in case of: unstable or boiling liquids, mixed hydrocarbons and petrochemical with unknown vapor pressures; sealed floating roof or external floating roof tank when barely valve communicated with the atmosphere; edge sealing system or deck materials is corrupt.

$$
L_{T}=L_{R}+L_{W D}+L_{F}+L_{D}
$$

Where $L_{T}$ is the total loss, lb/yr; $L_{R}$ is edge seal loss, lb/yr; $L_{W D}$ is extraction loss, $1 \mathrm{~b} / \mathrm{yr} ; L_{F}$ is deck loss, $\mathrm{lb} / \mathrm{yr} ; L_{D}$ is floating disc seal loss, $\mathrm{lb} / \mathrm{yr}$.

The calculation process takes into account the various influencing factors, and the main steps are proved by experiment or proved, and the result is high. On the other hand the calculation process is complex, many parameters required, the practical application is not convenient. What's more, the calculation factor of this method is most suitable for the petrochemical enterprises in the United States, the results would be less accurate in other countries and regions [7].

\section{Petroleum depot energy saving design guidelines Recommended Method}

This method makes use of Petroleum depot energy saving design guidelines (SH/T3002-2000) appendix A recommended calculation formula [8], suitable for the dome roof tank, floating roof tank and covered floating roof tank in storage of crude oil, gasoline and other light oil

Formulas for Large Breathing Loss:

$$
L_{W}=\frac{4 Q_{1} C \rho_{Y}}{D}
$$

Where $L_{W}$ is annual large breathing loss of floating roof tank, $\mathrm{kg} / \mathrm{a} ; Q_{1}$ is tank annual turnover; $C$ is adhesion coefficient of oil tank wall, $\mathrm{m}^{3} / 1000 \mathrm{~m}^{2} ; D$ is tank diameter, $\mathrm{m} ; \rho_{y}$ is oil density, $\mathrm{kg} / \mathrm{m}^{3}$.

Formulas for Small Breathing Loss:

$$
L_{S}=K_{4}\left(K_{5} F_{r} D+F_{f}\right) P^{*} M_{V} K_{C}
$$

Where $L_{S}$ is annual small breathing loss of floating roof tank, $\mathrm{kg} / \mathrm{a} ; \mathrm{Fr}$ is seal loss coefficient; $F_{f}$ is total loss coefficient of floating disc attachment; $P^{*}$ is vapor pressure function; $M_{V}$ is molar mass of oil and gas; $K_{C}$ is oil coefficient; $K_{4}$ and $K_{5}$ is unit conversion factor.

Petroleum depot energy saving design guidelines recommended method is amendments to the EPA method, often applied by Chinese petrochemical enterprises to calculate light oil emissions. This guide is based on China's own situation, on basis of the ideal gas state equation, and the empirical formula is put forward through the theoretical analysis [9]. The formula is more accurate for tank classification, but the calculation process of this method is complicated, and the formula lacks the perfect meteorological condition coefficient [10]. 


\section{Emission Coefficient Method}

The calculation range of liquid fuel emission coefficient method (gasoline, aviation gasoline vehicle high speed diesel engine, etc.), fuel (naphtha, liquefied petroleum gas, oil, chemical raw materials) (ethylene, propylene, toluene). Estimates shall put the enterprise as a point source, the calculation formula is as follows:

$$
L_{T}=C \times Q
$$

Where $L_{T}$ is total VOCs emissions from oil refineries, t/yr; $C$ is emission factor; $Q$ is crude oil consumption, $\mathrm{t} / \mathrm{yr}$.

Table1 EU Corinair1990 emission coefficient

\begin{tabular}{ccc}
\hline Refinery type & $\begin{array}{c}\text { Emission factor(g/kg oil } \\
\text { consumption) }\end{array}$ & Reliability \\
\hline modern refinery & 0.25 & $\mathrm{C}$ \\
Old refinery & 1.00 & $\mathrm{E}$ \\
\hline
\end{tabular}

Emission coefficient method is summarized by a large number of enterprises and organizations, according to a great quantity of actual production data, the calculation process is simple, suitable for the calculation of storage tank evaporation, long-term production process of transport losses and other equipment leakage. However, this method has obvious defects in estimating the breathing loss, make the results very limited [11].

\section{Loss of liquid petroleum products in bulk Estimation Method}

Loss of liquid petroleum products in bulk (GB11085-1989) [12] specifies method to estimate the loss of the bulk liquid petroleum products in storage, handling, transportation (including highway, railway, waterway transportation) and retail process. The rate of loss is drawn from a large number of statistical data. The emissions of tank breathing loss could be obtained according to the tank type, location, season, and oil type in table2, altitude corrected loss rate in table3.

Table2 Storage loss rate $(\%)$

\begin{tabular}{ccccc}
\hline \multirow{2}{*}{ Region } & \multicolumn{3}{c}{ Vertical metal tank } & $\begin{array}{c}\text { Concealed tank } \\
\text { and floating roof } \\
\text { tank }\end{array}$ \\
\cline { 2 - 4 } & \multicolumn{2}{c}{ gasoline } & Other oil & $\begin{array}{c}\text { Regardless of oil, } \\
\text { season }\end{array}$ \\
\cline { 2 - 4 } A & Spring and winter & $\begin{array}{c}\text { summer and } \\
\text { Autumn }\end{array}$ & $\begin{array}{c}\text { Regardless of } \\
\text { season }\end{array}$ & \\
B & 0.11 & 0.21 & & 0.01 \\
$\mathrm{C}$ & 0.05 & 0.12 & 0.01 & \\
\hline
\end{tabular}

According to the elevation of the site, the storage loss rate is adjusted according to table3:

Table3 Altitude corrected loss rate

\begin{tabular}{cc}
\hline Altitude, $\mathrm{m}$ & Increased loss, $\%$ \\
\hline $1000 \sim 2000$ & 21 \\
$2001 \sim 3000$ & 37 \\
$3001 \sim 4000$ & 55 \\
more than 4001 & 76 \\
\hline
\end{tabular}


Loss of liquid petroleum products in bulk estimation method is based on the field test of the evaporation loss of gasoline and commercial oil depot in the 1980s. It has the advantages of convenient calculation process and fast calculation speed. However, this standard is only applicable to automotive gasoline, lamp kerosene, diesel and lubricants, at the same time, the tank type and specifications of the tank are roughly divided and the accuracy of calculation result is very poor.

\section{Technical guidelines for the preparation of emission inventories of atmospheric volatile organic compounds (Trial) Recommended Method}

This method is compiled in reference of Environmental Protection Law of People's Republic of China, Law of the People's Republic of China on the Prevention and Control of Atmospheric Pollution, air quality standards etc. The VOCs emission sources are classified into five categories, including: biomass combustion source, fossil fuel combustion source, process emission source, solvent source and mobile source. The VOCs emission calculation formula applicable to process emission source is as follows [13]:

$$
E=\sum_{m} E F_{k, m} \times Q_{m}
$$

Where $k$ is VOCs emission source for process; $m$ represents province; $E$ is pollutant discharge level; $E F$ is pollutant emission factor; $Q$ is the amount of product produced in the process.

Technical guidelines for the preparation of emission inventories of atmospheric volatile organic compounds (Trial) recommended method divide the pollution source into a number of basic emission units such as the economic sector, technical characteristics, etc., and obtain the corresponding activity level information for each unit including the emission reduction effect, so as to calculate the pollutant emissions. The method is clear, the calculation speed is quick, the operability is strong, and it is suitable for the large-scale pollution discharge accounting by crude oil extraction, oil transportation and storage process. [14] However, the method is relatively rough in the classification of oil type, the type of tank, and the specific process, thus the calculation accuracy is low.

\section{Conclusions}

With the increasing emphasis on air pollution, VOCs management and sewage charges, the research on the unorganized emissions generated by the respiratory loss of storage tanks has become the focus of petrochemical enterprises. Several commonly used calculation methods include EPA recommended method, Petroleum depot energy saving design guidelines recommended method, emission coefficient method, Loss of liquid petroleum products in bulk estimation method and Technical guidelines for the preparation of emission inventories of atmospheric volatile organic compounds (Trial) recommended method, however, the five methods mentioned above have its own deficiency and limitations. The relevant production and management department should select the appropriate method to carry out the reasonable and effective VOCs calculation according to the actual application conditions, so as to adopt the environmental protection control measures targeted and provide the scientific basis for the further development of the environmental monitoring plan.

\section{Acknowledgements}

This work was financially supported National Natural Fund Project (61471171) and the Special Funds for Fundamental Scientific Research Business Fees in Central Universities (2015ZZD08). 


\section{References}

[1] Gan Mingjun. Analysis of the storage tank breathing loss during oil storage and transportation[J]. China Petroleum and Chemical Standard and Quality, 2016, 10:80-81.(in Chinese)

[2] Sabo E. Evaluating Petroleum Industry VOC Emissions in Delaware, New Jersey and Southeastern Pennsylvania, Final Report[R]. Baltimore, Maryland: MACTEC Federal Programs, Inc. 2003, 1-6.

[3] Hsu D J, Huang H L, Chien C H, et al. Potential exposure to VOCs caused by dry process photocopiers: results from a chamber study[J]. Bulletin of Environmental Contamination and Toxicology, 2005, 75(6):1150-5.

[4] Yamamoto H. Evaluation of Human Health Risks From Exposures to Four Air Pollutants in the Indoor and the Outdoor Environments in Tokushima, and Communication of the Outcomes to the Local People[J]. Journal of Risk Research, 2007, 10(6):841-851.

[5] Zhou Junliang. Analysis on the Causes and Disposal Measures of Fire and Explosion Accident in Petrochemical Enterprises[J]. Guangzhou Chemical Industry, 2016, 44(6):12-14.(in Chinese)

[6] U.S. Environmental Protection Agency. Emission factor documentation for AP-42 section 7 organic liquid storage tanks final report[R]. Washington D C: U.S. Environmental Protection Agency, 2006:38-116.

[7] Li Jin. Method for estimating non organized discharge of liquid storage tank[J]. Environment Protection in Petrochemical Industry, 2003, 26(4):51-53.(in Chinese)

[8] SH/T3002-2000, Petroleum depot energy saving design guidelines [S].

[9] Huo Yuxia, Li Farong, Gong Jilong, et al. Study on the influence and Countermeasures of the atmospheric environment in the petrochemical industry[J]. Environmental Science and technology, 2011, 34(7):195-199. (in Chinese)

[10] Lin Li, Lu Jun, He Xiaochu, et al. Comparison of calculation methods of Chinese and American storage tank breathing emissions[J]. Chemical Environmental Protection, 2012, 32(2):137-140.(in Chinese)

[11] Jia Zhihui. Risk analysis of tank farm and estimation of oil and gas evaporation loss in oil storage and transportation enterprise[D]. China University of Mining and Technology, 2014.(in Chinese)

[12] GB11085-1989,Loss of liquid petroleum products in bulk [S].

[13] Technical guidelines for the preparation of emission inventories of atmospheric volatile organic compounds (Trial).

[14] Liu Chang. Discussion on statistical method of volatile organic compounds (VOCs) emissions in petrochemical enterprises[J]. green science and technology, 2016(6):58-59.(in Chinese) 